The FASEB Journal express article 10.1096/fj.03-0216fje. Published online September 18, 2003.

\title{
Relaxin inhibits lipopolysaccharide-induced adhesion of neutrophils to coronary endothelial cells by a nitric oxide- mediated mechanism
}

\author{
Silvia Nistri, ${ }^{*}$ Laura Chiappini, ${ }^{*}$ Chiara Sassoli ${ }^{\dagger}$ and Daniele Bani* \\ Department of Anatomy, Histology and Forensic Medicine, *Section of Histology and ${ }^{\dagger}$ Section \\ of Anatomy, University of Florence, v.le G. Pieraccini, 6 - I-50139 Florence, Italy \\ Corresponding author: Daniele Bani, Dipartimento di Anatomia, Istologia e Medicina Legale. \\ Sezione di Istologia Università di Firenze V.le G.Pieraccini, 6 - I-50139 Florence, Italy. E-mail: \\ daniele.bani@unifi.it
}

\begin{abstract}
Neutrophil margination within blood vessels is an early finding during myocardial ischemia and can result in myocardial tissue injury. This phenomenon depends on the endothelial expression of adhesion molecules, which allow leukocyte extravasation. The hormone relaxin (RLX) was found to protect against experimental myocardial injury and to reduce neutrophil extravasation into the inflamed tissues. This study addresses the role of RLX in down-regulating endothelial adhesiveness to neutrophils and the possible involvement of NO, an anti-adhesive molecule, in the mechanism of action of RLX. Lipopolysaccharide (LPS)-primed rat coronary endothelial (RCE) cells and neutrophils were co-cultured and their adhesion was quantified in the absence and presence of RLX, alone or together with the NO-synthase inhibitor L-NMMA. Inactivated RLX was used as control for specificity of the RLX effect. A 24-h incubation of LPS-primed RCE cells with RLX (60 and $600 \mathrm{ng} / \mathrm{ml}$ ) caused a significant reduction of adherent neutrophils and of endothelial expression of the adhesion molecules P-selectin and VCAM-1 protein and mRNA, evaluated by immunohistochemistry, Western blot, and RT-PCR. These effects of RLX were blunted by L-NMMA and were not reproduced by inactivated RLX. These findings suggest that RLX has anti-inflammatory properties that could be of benefit in ischemic heart disease.
\end{abstract}

Key words: P-selectin • VCAM-1 • ICAM-1

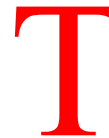

The margination of neutrophils within the vascular compartment is an early finding during myocardial ischemia and represents a potential threat to the heart $(1,2)$. When neutrophils encounter endothelial cells in the presence of activating stimuli, a sequence of events is initiated that culminates in tissue injury (3). This process prompts neutrophils to adhere to and pass through the vascular endothelium, thus reaching the interstitium where they undergo activation and release harmful oxygen-derived free radicals and lysosomal enzymes (4). Normally, the endothelium inhibits adherence of leukocytes by producing antiadhesive factors, such as nitric oxide (NO; 5, 6), and by expressing low levels of endothelial cell adhesion molecules (ECAMs), a generic term used to identify different types of surface glycoproteins based on their common function (7). Inflammatory mediators generated during myocardial ischemia can stimulate the expression of ECAMs. These molecules include early-phase proteins, 
such as P-selectin, which is held responsible for leukocyte rolling, as well as late-phase proteins, such as E-selectin, vascular cell adhesion molecule (VCAM)-1, and intercellular adhesion molecule (ICAM)-1, which appear later and are involved in firm adhesion of leukocytes to the vascular endothelium that allows leukocyte extravasation into the tissue (6). NO itself can reduce the expression of ECAMs, likely by interfering with the activation of the transcription factor NF$\kappa \mathrm{B}$ or with its binding to the ECAM gene promoters $(8,9)$. In fact, in vivo studies in laboratory mammals have shown that both administration of NO synthesis inhibitors and targeted disruption of constitutive NO synthase (NOS) I and III genes cause an increased amount of leukocytes adherent to the vascular endothelium $(5,6,10)$.

Recently, evidence has been provided that the peptide hormone relaxin (RLX), a member of the insulin/IGF superfamily (11), is a potent stimulator of endogenous NO biosynthesis in cultured rat coronary endothelial cells, acting by an overexpression of inducible NOS II (12). Experiments in rats subjected to cardiac ischemia/reperfusion have shown that RLX protects against myocardial injury, an effect that is accompanied by a marked reduction of neutrophil extravasation into the tissue (13). On these grounds, it appears that RLX could exert an antiinflammatory effect by interfering with endothelial-leukocyte interactions. The current study was designed to test this hypothesis by using an in vitro co-culture model of rat coronary endothelial cells and neutrophils, paying special attention to the possible mechanisms of action of RLX at the endothelial cell level.

\section{MATERIALS AND METHODS}

\section{Cells and reagents}

Rat coronary endothelial (RCE) cell cultures were obtained as described previously (14) and maintained in M199 medium containing 10\% fetal calf serum, 10\% newborn calf serum, 250 $\mathrm{IU} / \mathrm{ml}$ penicillin, $0.626 \mu \mathrm{g} / \mathrm{ml}$ amphotericin, and $250 \mu \mathrm{g} / \mathrm{ml}$ streptomycin. Unless otherwise specified, all the reagents used were from Sigma (St Louis, MO). Sera for cell culture were from Gibco BRL (Paisley, Scotland). Cell culture plastic ware was from Falcon (Becton Dickinson Europe, Meylan, France). With the isolation procedure used, RCE cell cultures attain a degree of purity ranging between 96 and 98\%, as evaluated by fluorescent LDL uptake (14). Purified porcine RLX (2500 to $3000 \mathrm{U} / \mathrm{mg}$ ) is a generous gift of O. D. Sherwood. Inactivated RLX (iRLX) was obtained by blockade of functional arginine residues by reaction with cyclohexanedione followed by dialysis of the unbound reagent against distilled water, according to the method of Büllesbach and Schwabe (15).

\section{Adhesion assay}

RCE cells at the $1^{\text {st }}$ and $2^{\text {nd }}$ culture passage were grown to confluence on round glass coverslips, $1.4 \mathrm{~mm}$ in diameter (Knittel Glaser, Braunschweig, Germany), placed into 24-well multiplates. Neutrophil adhesion assay was performed as summarized in Fig. 1. The following sets of RCE cell cultures were prepared: i) cells incubated with RLX at the concentrations of 6, 60, and 600 $\mathrm{ng} / \mathrm{ml}$ for $24 \mathrm{~h}$ (the time point of RLX addition is referred to as h 0 ); ii) cells incubated with RLX $(60 \mathrm{ng} / \mathrm{ml})$ for $24 \mathrm{~h}(\mathrm{~h} 0)$ and with the NOS inhibitor $\mathrm{N}^{\mathrm{G}}$-monomethyl-L-arginine (L-NMMA, $10^{-4} \mathrm{M}$ ) for the last $5 \mathrm{~h}$ (h 19); iii) cells incubated with iRLX (60 ng/ml) for $24 \mathrm{~h}$ in the place of authentic RLX; iv) cells treated with L-NMMA alone for $5 \mathrm{~h}$; v) cells not subjected to any 
treatment, used as controls. Four hours before addition of neutrophils for the adhesion assay (h 20), the RCE cell cultures were primed with E. coli lipopolysaccharide (LPS, $10 \mu \mathrm{g} / \mathrm{ml}$ ) as proinflammatory stimulus to induce or enhance the expression of ECAMs $(16,17)$. LPS was not added to a control set of RCE cells, which is referred to as basal culture. Neutrophils were isolated from whole blood of rats pretreated with an oral administration of $50 \mathrm{mg}$ warfarin (DuPont Pharma, Florence, Italy) in $0.5 \mathrm{ml}$ saline. Blood $(10 \mathrm{ml})$, anticoagulated with $3.8 \%$ sodium citrate, was collected by cardiac puncture. Neutrophils were obtained by dextran sedimentation followed by Ficoll-Paque density gradient centrifugation and hypotonic lysis for the removal of residual erythrocytes. Purity of neutrophil preparations ranged between 92 and $96 \%$, as evaluated by Giemsa stain. The final neutrophil pellet was suspended in M199 medium containing $10 \%$ fetal calf serum. Cell viability checked by trypan blue exclusion was $>95 \%$. Neutrophils were primed with LPS $(10 \mu \mathrm{g} / \mathrm{ml})$ for $30 \mathrm{~min}$. at $37^{\circ} \mathrm{C}$ and then aliquots containing $\sim 10^{5}$ cells were added to each RCE cell culture (h 24). Co-cultures were maintained for $15 \mathrm{~min}$. at $37^{\circ} \mathrm{C}$. After thorough rinsing in phosphate-buffered saline (PBS) to remove unbound neutrophils, the co-cultures were fixed in formaldehyde $4 \%$ in PBS and counterstained with hematoxylin for light microscopic examination. Two independent experiments, each in triplicate, were performed. In each sample, the numbers of adherent neutrophils and RCE cells were counted in five randomly chosen microscopical fields at a $\times 200$ final magnification (test area: $22,750 \mu \mathrm{m}^{2}$ ). Values obtained from two different observers were averaged.

To assess the contribution of different ECAMs to the overall adhesive interactions between LPSprimed RCE cells and neutrophils, additional experiments with blocking antibodies against endothelial ECAMs were performed. RCE cells were grown to confluence on round glass coverslips, incubated or not with LPS $(10 \mu \mathrm{g} / \mathrm{ml})$ for $4 \mathrm{~h}$. Thirty minutes before neutrophil addition, the cell cultures were treated with polyclonal antibodies against P-selectin $(60 \mu \mathrm{g} / \mathrm{ml}$, raised in goat, Santa Cruz Biotechnology, Santa Cruz, CA), VCAM-1 (60 $\mu \mathrm{g} / \mathrm{ml}$, raised in rabbit, Santa Cruz), and ICAM-1 (40 $\mu \mathrm{g} / \mathrm{ml}$, raised in mouse, Chemicon, Temecula, CA) added directly to the culture medium. Finally, LPS-activated neutrophils were added and co-cultures were maintained for $15 \mathrm{~min}$ at $37^{\circ} \mathrm{C}$. Upon rinsing, fixation, and staining, the numbers of adherent neutrophils and RCE cells were counted, as described above. A replicate experiment was performed. No experiments with anti-E-selectin antiserum were performed because, in our experiment, this adhesion molecule was not expressed by RCE cells, either in basal conditions or upon priming with LPS, as revealed by immunocytochemistry, Western blot, and RT-PCR (see below).

\section{Immunocytochemistry for ECAMs}

RCE cells at the $1^{\text {st }}$ and $2^{\text {nd }}$ culture passage were grown to confluence on round glass coverslips, $1.4 \mathrm{~mm}$ in diameter; placed into 24-well multiplates; and incubated with RLX (60 ng/ml), RLX and L-NMMA, or iRLX as described above. Basal and LPS-primed RCE cells were the controls. Upon fixation in $4 \%$ formaldehyde in PBS, the cells were immunostained with polyclonal antibodies against P-selectin (1:100, raised in goat, Santa Cruz), E-selectin (1:100, raised in rabbit, Santa Cruz), VCAM-1 (1:100, raised in rabbit, Santa Cruz), and ICAM-1 (1:200, raised in mouse, Chemicon), following the supplier's instructions. Immune reaction was revealed by biotinylated anti-goat (1:150), anti-rabbit (1:600), or anti-mouse (1:300) secondary antibodies and avidin-peroxidase complex (Dako, Glostrup, Denmark) by using 3-3' diaminobenzidine as 
chromogen and hematoxylin for nuclear counterstaining. Two different sets of RCE cell cultures were immunostained for each adhesion molecule assayed. Observations were performed on at least five different microscopical fields at a $\times 400$ final magnification.

\section{Western blot for ECAMs}

RCE cells at the $1^{\text {st }}$ and $2^{\text {nd }}$ culture passage were grown to confluence into $25 \mathrm{~cm}^{2}$ flasks and incubated with RLX (60 ng/ml), or RLX and L -NMMA, as described above. Basal and LPSprimed RCE cells were the controls. Upon $24 \mathrm{~h}$, cells were processed for Western blot as described in a previous article (12). Upon SDS-PAGE $(200 \mathrm{~V}, 1 \mathrm{~h})$ and blotting $(150 \mathrm{~V}, 1 \mathrm{~h})$, nitrocellulose membranes were incubated overnight at $4^{\circ} \mathrm{C}$ under stirring with the same antibodies used above (P-selectin, 1:100; VCAM-1, 1:200; E-selectin, 1:100; ICAM-1, 1:1000). Immune reaction was revealed by peroxidase-labeled secondary antibodies (Vector, Burlingame, CA, 1:10,000) by using the chemiluminescent substrate ECL (Amersham, Milan, Italy) and exposure to high-sensitivity photographic film (Biomax ML, Kodak, Rochester, NY). The relative intensities of the bands were quantified by densitometric analysis by using Scion Image Beta 4.0.2 image analysis program (Scion Corp., Frederick, MD). The values were normalized to the corresponding $\beta$-actin values and expressed as percent changes of the values of basal RCE cells. Values are the mean $( \pm$ SEM) of three separate experiments.

\section{Assay for ECAM mRNAs}

Expression levels of mRNA for the ECAMs assayed were measured by semiquantitative reverse transcription-PCR (RT-PCR). For this purpose, RCE cells at the $1^{\text {st }}$ and $2^{\text {nd }}$ culture passage were grown to confluence into $25 \mathrm{~cm}^{2}$ flasks and incubated with RLX $(60 \mathrm{ng} / \mathrm{ml})$ or RLX and LNMMA as described above. Basal and LPS-primed RCE cells were the controls. Total cellular RNA was extracted by using Trizol Reagent (Gibco-BRL) according to the manufacturer's protocol and quantified spectrophotometrically at a $260 \mathrm{~nm}$ wavelength. Then, $100 \mathrm{ng}$ of total RNA was reverse-transcribed and amplified with SuperScript ${ }^{\mathrm{TM}}$ One-Step ${ }^{\mathrm{TM}}$ RT-PCR System (Invitrogen, Groningen, The Netherlands) in a total volume of $50 \mu \mathrm{l}$. After cDNA synthesis for $30 \mathrm{~min}$ at $55^{\circ} \mathrm{C}$ the samples were pre-denatured for $2 \mathrm{~min}$ at $94^{\circ} \mathrm{C}$; the first-strand cDNA was subjected to 35 cycles of PCR performed at $94^{\circ} \mathrm{C}$ for $15 \mathrm{~s}, 58^{\circ} \mathrm{C}$ for $30 \mathrm{~s}$ (P-selectin and VCAM1) or $55^{\circ} \mathrm{C}$ for $30 \mathrm{~s}$ (E-selectin and ICAM-1), and $72^{\circ} \mathrm{C}$ for $1 \mathrm{~min}$; the final extension step was performed at $72^{\circ} \mathrm{C}$ for $5 \mathrm{~min}$. Internal standards for quantification of ECAM cDNAs were generated by amplifying $\beta$-actin mRNA (annealing temperature: $55^{\circ} \mathrm{C}$ ). The following rat genespecific primers were used: P-selectin mRNA (GenBank accession number: L23088), forward 5'-CTC TGG GGG ACT TCT CCT TC-3' and reverse 5'-AGG TTG GCA ATG GTT CAC TC3'; VCAM-1 mRNA (GenBank accession number: NM 012889), forward 5'- TTG GCT CCT GAT GTT TAC CC-3' and reverse 5'-GCA CCC TCA TGT AGC CTT GT-3'; E-selectin mRNA (GenBank accession number: NM138879.1), forward 5'-TGC CCA CGG AGT CAG GAA AT3' and reverse 5'-ACT GCA TTC AAC CTG GGC TG-3'; ICAM-1 mRNA (GenBank accession number: NM012967.1), forward 5'-AGG TCT CAG AAG GGG ACC AA-3' and reverse 5'GGT CAG ATT AGG GGC TGG AT-3'; $\beta$-actin mRNA (GenBank accession number: NM 031144), forward 5'-CCA ACC GTG AAA AGA TGA CC-3' and reverse 5'- AGA GGT CTT TAC GGA TGT CA-3'. Expected lengths of amplified fragments were 309, 308, 306, 361, and 539 base pairs for P-selectin, VCAM-1, E-selectin, ICAM-1, and $\beta$-actin, respectively. PCR 
products were separated by electrophoresis on a $2 \%$ agarose gel, and the ethidium bromidestained bands were quantified by densitometric analysis by using the Scion Image Beta 4.0.2 image analysis program. Within the linear range of amplification, the values of P-selectin, VCAM-1, and ICAM-1 amplification products were normalized to the corresponding $\beta$-actin values and expressed as percent changes of the values of basal RCE cells. E-selectin amplification product were never detected, despite several experiments at different PCR conditions. The reported values are the mean ( \pm SEM) of three separate experiments.

\section{Statistical analysis}

Statistical comparison of differences between the experimental groups was performed by using either one-way ANOVA test followed by Student-Newman-Keuls multiple comparison test or Student's $t$-test for unpaired values. $P \leq 0.05$ was considered significant. Calculations were performed by using a GraphPad Prism 2.0 statistical program (GraphPad Software, San Diego, CA).

\section{RESULTS}

By light microscopy, RCE cells primed with LPS showed a marked increase in the amount of adherent neutrophils compared with the unprimed cells in basal cultures (Fig. $2 A, \underline{B})$. A $24 \mathrm{~h}$ incubation with RLX caused a reduction of adherent neutrophils, clearly appreciable at 60 and $600 \mathrm{ng} / \mathrm{ml}$ RLX (Fig. 2C, $\underline{\text { ) }}$. The effect of RLX on neutrophil adhesion was blunted by coincubation with the NOS inhibitor L-NMMA and was far less evident with iRLX substituted for authentic RLX (Fig. 2E, $\underline{F}$ ). Incubation of RCE cells with L-NMMA alone did not substantially influence neutrophil adhesion (data not shown). Quantitative analysis confirmed the visual observations, for it showed that the number of adherent neutrophils per RCE cell was significantly reduced by 60 and $600 \mathrm{ng} / \mathrm{ml}$ RLX but not by RLX plus L-NMMA or iRLX. LNMMA alone did not significantly change the LPS-induced adhesion of neutrophils to RCE cells (Fig. 3). Control adhesion experiments with function-blocking antibodies against P-selectin, VCAM-1, and ICAM-1 showed that the tested antisera markedly reduced the number of neutrophils adherent to RCE cells, as judged by the neutrophil/RCE cell ratio (basal: $0.15 \pm 0.02$; LPS: $0.43 \pm 0.06$; LPS + anti-P-selectin: $0.28 \pm 0.07$; LPS + anti-VCAM-1: $0.28 \pm 0.06$; LPS + antiICAM-1: $0.22 \pm 0.03)$.

At a visual examination of immunolabeled RCE cells (Fig. 4), the staining intensity for Pselectin, VCAM-1 and ICAM-1 appeared enhanced in LPS-primed RCE cells compared with the unprimed controls. RLX $(60 \mathrm{ng} / \mathrm{ml})$ seemed to decrease the staining intensity for P-selectin and VCAM-1 but not for ICAM-1. Of note, RLX plus L-NMMA caused little or no changes and iRLX also appeared ineffective (data not shown). Western blot and RT-PCR analysis (Figs. 5, $\underline{6}$ ) fitted well with the immunocytochemical findings. In both cases, quantitative analysis showed that RLX caused a clear-cut, significant reduction of the expression of P-selectin and VCAM-1 protein and mRNA induced by LPS priming in RCE cells. The effect of RLX was abolished by the concurrent incubation with L-NMMA. On the other hand, RLX was ineffective in reducing ICAM-1 protein and mRNA in LPS-primed RCE cells. Expression of E-selectin was never detected in either basal or LPS-primed RCE cells, regardless the assay method used (data not shown). 


\section{DISCUSSION}

The present study provides first experimental evidence that the peptide hormone RLX, acting through a NO-dependent mechanism, markedly reduces the adhesiveness of vascular endothelial cells to neutrophils upon activation by LPS as proinflammatory stimulus, an effect that is apparently exerted by a down-regulation of the expression of some early-phase and late-phase ECAMs, namely P-selectin and VCAM-1. The number of neutrophils adhering to RCE cells upon LPS priming was significantly reduced by a $24 \mathrm{~h}$ incubation with RLX, with a maximal effect at the hormone concentration of $60 \mathrm{ng} / \mathrm{ml}$. At these concentration and time of exposure, RLX significantly reduced the expression of P-selectin and VCAM-1 mRNA and protein by RCE cells induced by a $4 \mathrm{~h}$ priming with LPS, as shown by RT-PCR, immunocytochemistry and Western blot. Conversely, RLX did not substantially influence ICAM-1 expression, a finding that could account for the residual amounts of neutrophils adherent to RCE cells observed in the RLX-treated cultures.

Activation of endothelial cells and leukocytes resulting in reciprocal adhesion and directed migration of the latter cells to the inflamed site is an early and crucial event in the inflammatory tissue injury. RLX appears to interfere with this phenomenon, thereby exerting antiinflammatory effects. Of note, parallel experiments performed by us on isolated human neutrophils indicate that RLX, at the same concentrations used in the present study, also reduces the activation and chemotaxis of these cells (Masini et al., unpublished data). This novel property of RLX may account for at least part of the previously reported beneficial effects of this hormone in animal models of inflammation, such as rats subjected to cardiac ischemia and reperfusion and sensitized guinea pigs with allergic lung disease due to antigen inhalation, in which a marked reduction of leukocytes infiltrating the inflamed tissue was observed upon systemic treatment with $\operatorname{RLX}(13,18)$.

In the present study, the inhibitory effect of RLX on endothelial adhesiveness to neutrophils clearly emerges as a specific property of this hormone because it could not be reproduced by replacing authentic RLX with iRLX, which is similar to RLX except for its inability to bind to RLX receptors (15). The moderate, not statistically significant reduction of neutrophils adherent to RCE cells observed upon iRLX treatment is likely to be attributed to a residual biological activity of the iRLX preparation, possibly due to incomplete inactivation by cyclohexanedione of some RLX molecules.

Conceivably, the mechanism by which RLX exerts its anti-adhesive effect relies on the stimulation of endogenous NO synthesis by RCE cells, which has been shown to depend chiefly on the up-regulation of NOS II expression (12). In fact, the present findings show that coincubation with the NOS inhibitor L-NMMA blunted the RLX-induced decrease of neutrophil adhesion and endothelial expression of P-selectin and VCAM-1. Indeed, NO is known as a physiological inhibitor of endothelial-leukocyte interaction $(8,9)$ and it is worth noting that NO can suppress the expression of P-selectin and VCAM-1 by activated endothelial cells $(5,19,20)$.

The present findings may have important functional implications because they provide further support to the hypothesis that RLX, which is both secreted and bound specifically by the heart (21-23), could have a physiological role as an autocrine cardioprotective factor against the detrimental effects of ischemic disease (13). On these grounds, the presence of circulating RLX 
in women during fertile life may contribute to explain the low incidence of coronary heart disease compared with age-matched men and postmenopausal women $(24,25)$.

\section{ACKNOWLEDGMENTS}

The authors gratefully acknowledge David O. Sherwood, Department of Molecular and Integrative Physiology, University of Illinois at Urbana-Campaign, for having provided purified porcine relaxin as a gift. Many thanks are also due to Patrizio Guasti, Daniele Guasti, and Laura Calosi, Department of Anatomy, Histology and Forensic Medicine, for skillful technical assistance. The administrative support of Rita Scantimburgo is also acknowledged. This work was supported by a grant from the Italian Ministry for Education, University and Research (MIUR), Co-funding of Research Programs of National Interest (PRIN), years 2000-2001, and by funds from the University of Florence.

\section{REFERENCES}

1. Engler, R. L., Dahlgren, M. D., Morris, D., Peterson, M. A., and Schmid-Schönbein, G. W. (1986) Role of leukocytes in the response to acute myocardial ischemia and reflow in dogs. Am. J. Physiol. 251, H314-H323

2. Pietersma, A., de Jong, N., Koster, J. F., and Sluiter, W. (1994) Effect of hypoxia on adherence of granulocytes to endothelial cells in vitro. Am. J. Physiol. (Heart Circ. Physiol. 36) 267, H874-H879

3. Anderson, B. O., Brown, J. M., and Harken, A. H. (1991) Mechanisms of neutrophilmediated tissue injury. J. Surg. Res. 51, 170-179

4. McCord, J. M. (1985) Oxygen-derived free radicals in post-ischemic tissue injury. N. Engl. J. Med. 312, 159-163

5. Kubes, P., Suzuki, M., and Granger, D. N. (1991) Nitric oxide: an endogenous modulator of leukocyte adhesion. Proc. Natl. Acad. Sci. USA 88, 4651-4655

6. Laroux, F. S., Lefer, D. J., Kawachi, S., Scalia, R., Cockrell, A. S., Gray, L., van der Heyde, H., Hoffmann, J. M., and Grisham, M. B. (2000) Role of nitric oxide in the regulation of acute and chronic inflammation. Antiox. Redox. Signal 2, 391-396

7. Sluiter, W., Pietersma, A., Lamers, J. M. J., and Koster, J. F. (1993) Leukocyte adhesion molecules on the vascular endothelium: their role in the pathogenesis of cardiovascular disease and the mechanism underlying their expression. J. Cardiovasc. Pharmacol. 22, suppl. 4, S37-S44

8. Peng, H. B., Spiecker, M., and Liao, J. K. (1998) Inducible nitric oxide: an autoregulatory feedback inhibitor of vascular inflammation. J. Immunol. 161, 1970-1976

9. Spiecker, M., and Liao, J. K. (1999) Assessing induction of I kappa B by nitric oxide. Methods Enzymol. 300, 374-388 
10. Lefer, D. J., Jones, S. P., Girod, W. G., Baines, A., Grisham, M. B., Cockrell, A. S., Huang, P. L., and Scalia, R. (1999) Leukocyte-endothelial cell interactions in nitric oxide synthasedeficient mice. Am. J. Physiol. 276, H1943-H1950

11. Bani, D. (1997) Relaxin: a pleiotropic hormone. Gen. Pharmacol. 28, 13-22

12. Failli, P., Nistri, S., Quattrone, S., Mazzetti, L., Bigazzi, M., Bani Sacchi, T., and Bani, D. (2001) Relaxin up-regulates inducible nitric oxide synthase expression and nitric oxide generation in rat coronary endothelial cells. FASEB J. Dec. 14, 10.1096/fj.01-0569fje.

13. Bani, D., Masini, E., Bello, M. G., Bigazzi, M., and Bani Sacchi, T. (1998) Relaxin protects against myocardial injury caused by ischemia and reperfusion in rat heart. Am. J. Pathol. 152, 1367-1376

14. Nistri, S., Mazzetti, L., Failli, P., and Bani, D. (2002) High-yield method for isolation and culture of endothelial cells from rat coronary blood vessels suitable for analysis of intracellular calcium and nitric oxide biosynthetic pathway. Biol. Procedures Online 4, 3237

15. Büllesbach, E. E., and Schwabe, C. (1988) On the receptor binding sites of relaxins. Int. J. Pept. Protein Res. 32, 361-367

16. Bachschmid, M., Thurau, S., Zou, M. H., and Ullrich, V. (2003) Endothelial cell activation by endotoxin involves superoxide/NO-mediated nitration of prostacyclin synthase and thromboxane receptor stimulation. FASEB J. 17, 914-916

17. Luscinskas, F. W., Cybulsky, M. I., Kiely, J. M., Peckins, C. S., Davis, V. M., and Gimbrone, M. A., Jr. (1991) Cytokine-activated human endothelial monolayers support enhanced neutrophil transmigration via a mechanism involving both endothelial-leukocyte adhesion molecule-1 and intercellular adhesion molecule-1. J. Immunol. 146, 1617-1625

18. Bani, D., Ballati, L., Masini, E., Bigazzi, M., and Bani Sacchi, T. (1997) Relaxin counteracts asthma-like reaction induced by inhaled antigen in sensitized guinea pigs. Endocrinology 138, 1909-1915

19. Davenpeck, K. L., Gauthier, T. W., and Lefer, A. M. (1994) Inhibition of endothelialderived nitric oxide promotes P-selectin expression and actions in the rat microcirculation. Gastroenterology 107, 1050-1058

20. De Caterina, R., Libby, P., Peng, H. B., Thannickal, V. J., Rajavashisth, T. B., Gimbrone, M. A., Jr., Shin, W. S., and Liao, J. K. (1995) Nitric oxide decreases cytokine-induced endothelial activation. Nitric oxide selectively reduces endothelial expression of adhesion molecules and proinflammatory cytokines. J. Clin. Invest. 96, 60-68

21. Osheroff, P. L., and Ho, W. (1993) Expression of relaxin mRNA and relaxin receptors in postnatal and adult rat brain and hearts. J. Biol. Chem. 268, 15193-15199 
22. Taylor, M. J., and Clark, C. L. (1994) Evidence for a novel source of relaxin: atrial cardiocytes. J. Endocrinol. 143, R5-R8

23. Hsu, S. Y., Nakabayashi, K., Nishi, S., Kumagai, J., Kudo, M., Sherwood, O. D., and Hsueh, A. J. W. (2002) Activation of orphan receptors by the hormone relaxin. Science 295, 671673

24. Wenger, N. K., Speroff, L., and Packard, B. (1993) Cardiovascular health and disease in women. N. Engl. J. Med. 329, 247-256

25. Hu, F. B., Stampfer, M. J., Manson, J. E., Grodstein, F., Colditz, G. A., Speizer, F. E., and Willett, W. C. (2000) Trends in the incidence of coronary heart disease and changes in diet and lifestyle in women. N. Engl. J. Med. 343, 530-537

Received March 26, 2003; accepted July 18, 2003. 
Fig. 1

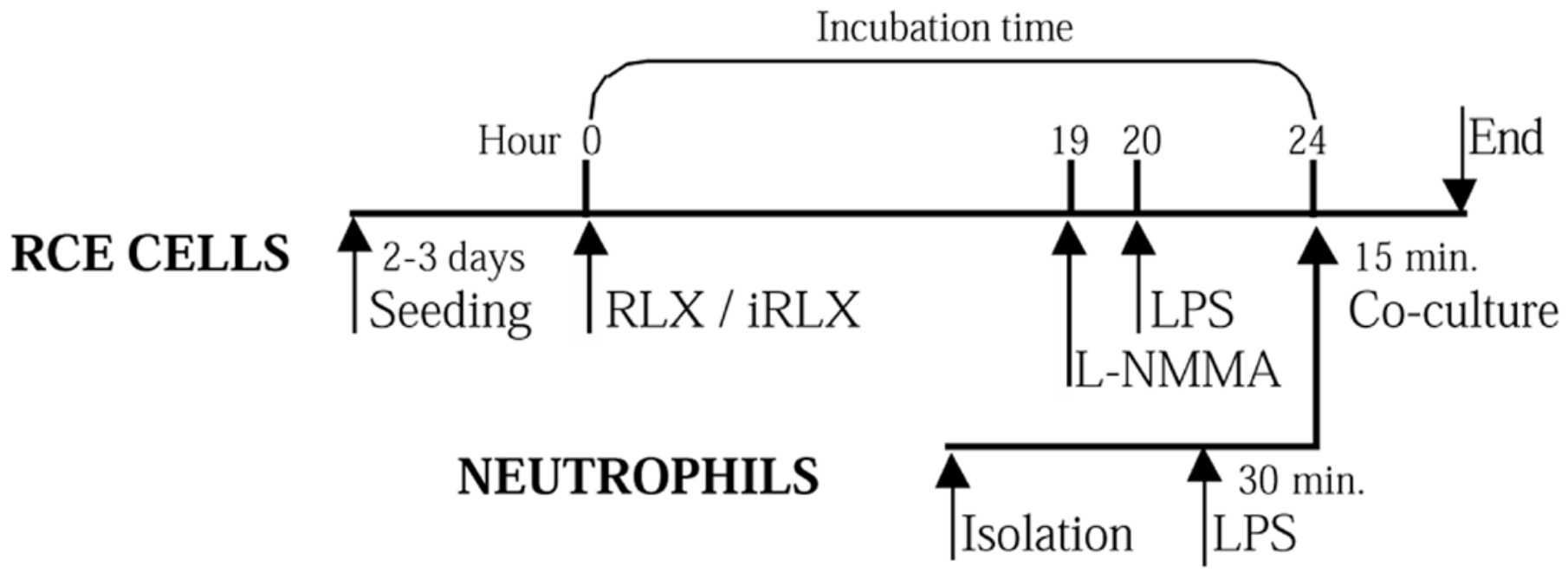

Figure 1. Schematic diagram of the adhesion experiment. 
Fig. 2
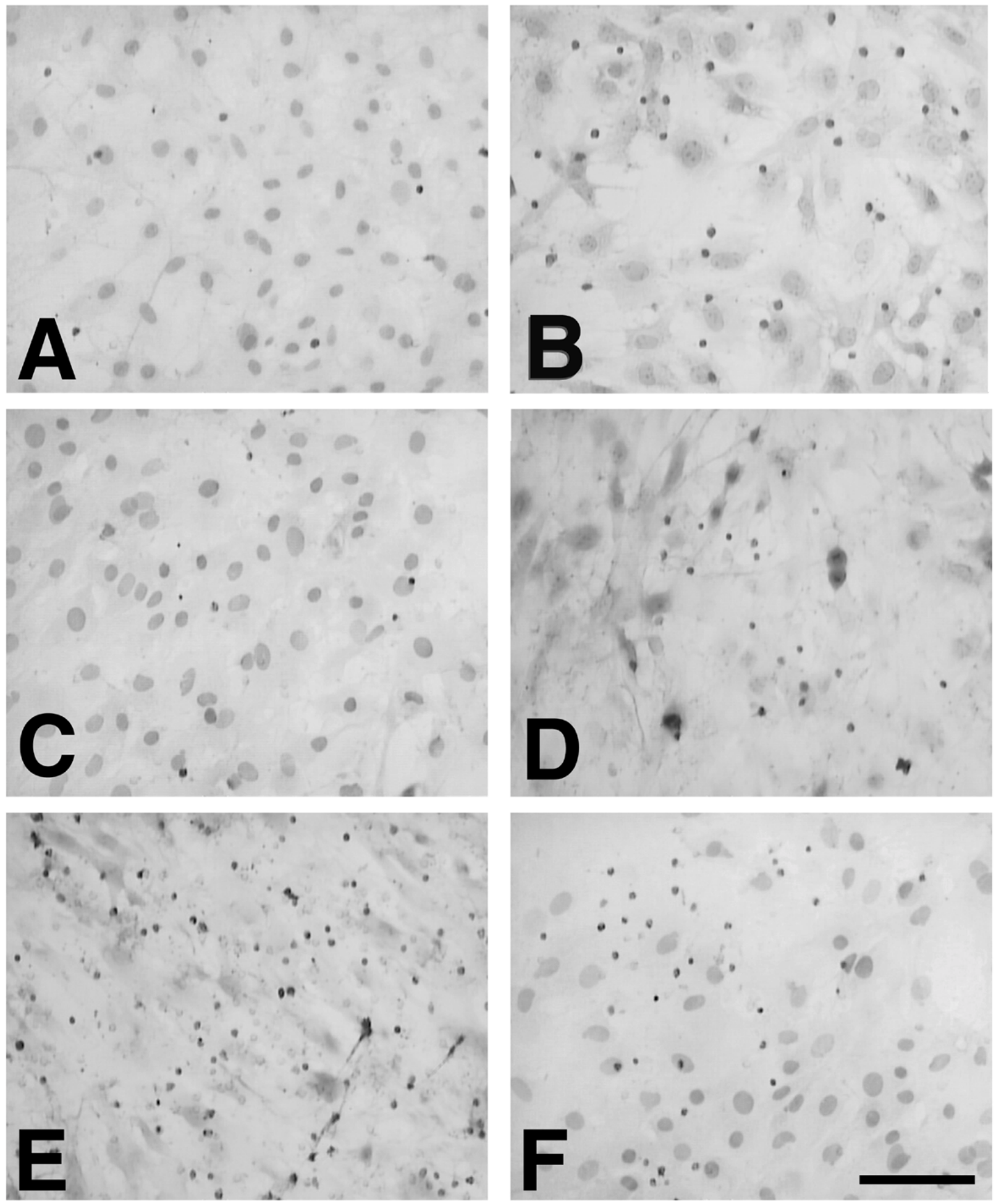

Figure 2. Representative light micrographs of neutrophils adhering to RCE cells in different experimental conditions. $\boldsymbol{A}$ ) basal; $\boldsymbol{B})$ LPS activation; $\boldsymbol{C})$ RLX $60 \mathrm{ng} / \mathrm{ml}$ and LPS; $\boldsymbol{D})$ RLX $600 \mathrm{ng} / \mathrm{ml}$ and LPS; $\boldsymbol{E}$ ) RLX $60 \mathrm{ng} / \mathrm{ml} \mathrm{plus}$ L-NMMA and LPS; and $\boldsymbol{F}$ ) iRLX $60 \mathrm{ng} / \mathrm{ml}$ and LPS. Nuclei are counterstained with hematoxylin. Magnification: $\times 200$. Bar $=100 \mu \mathrm{m}$. 
Fig. 3

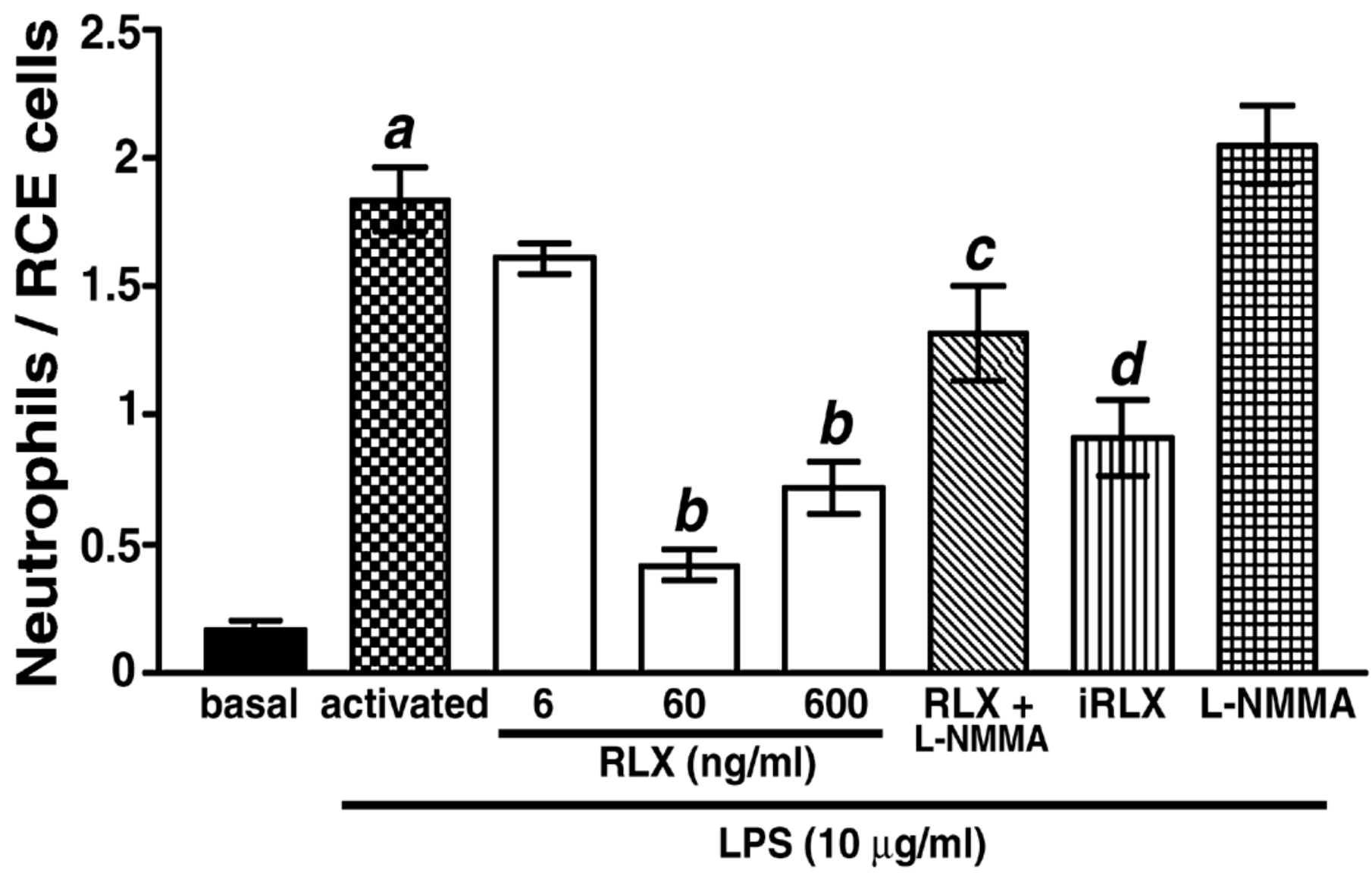

Figure 3. Bar chart showing the neutrophil/RCE cell ratio in the different experimental conditions. Bars are mean \pm SEM of six separate experiments. Significance of differences (one-way ANOVA): $\boldsymbol{a}$ ) $P<0.001 \mathrm{vs.} \mathrm{basal;} \boldsymbol{b}) P<0.001 \mathrm{vs}$. LPS-activated RCE cells; $\boldsymbol{c}) P<0.001$ vs. RLX $60 \mathrm{ng} / \mathrm{ml}$ and LPS; and $\boldsymbol{d}$ ) $P<0.05 \mathrm{vs.} \mathrm{RLX} 60 \mathrm{ng} / \mathrm{ml}$ and LPS. 
Fig. 4

\section{P-selectin}
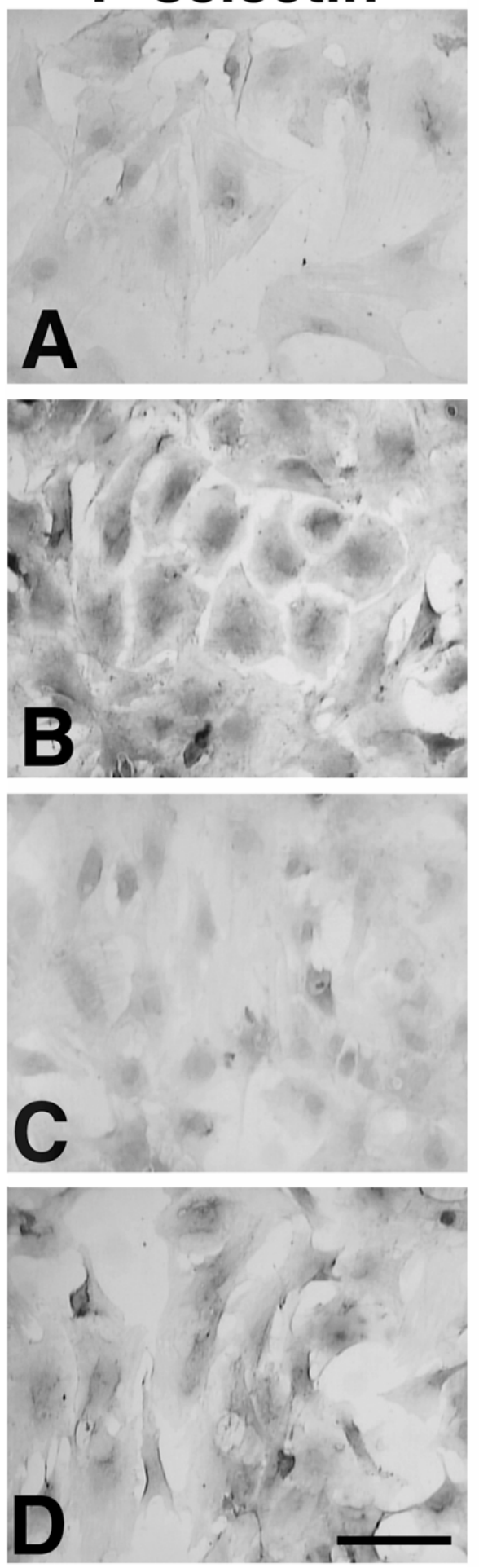

VCAM-1
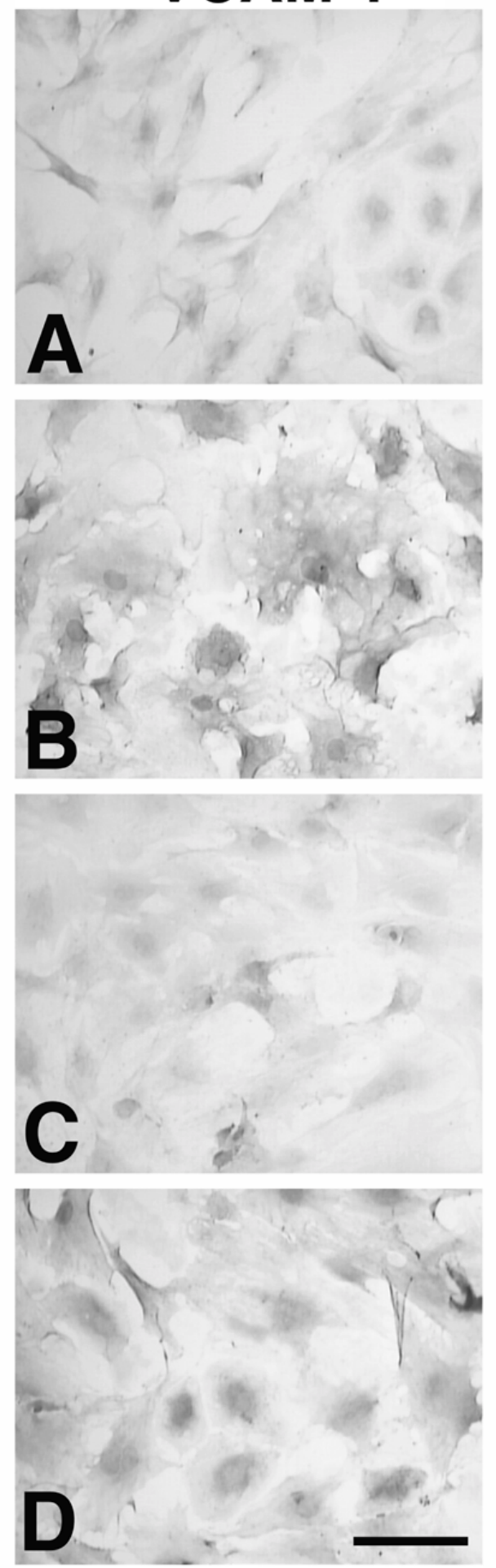

ICAM-1
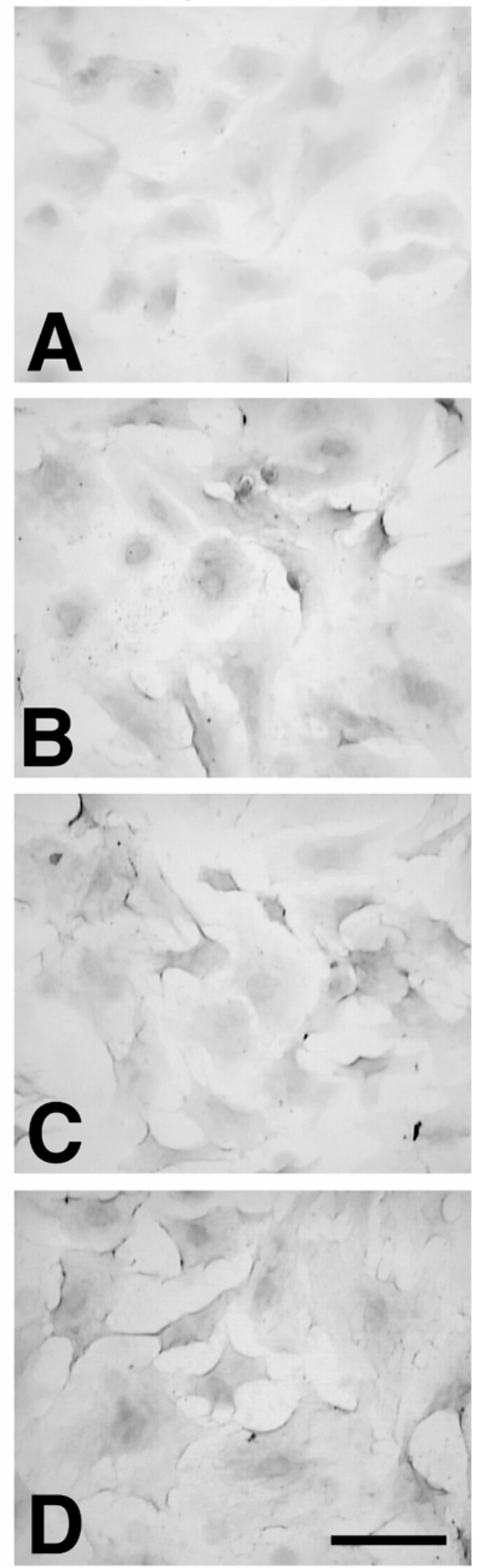

Figure 4. Representative light micrographs of P-selectin, VCAM-1, and ICAM-1 immunocytochemistry in RCE cells in different experimental conditions. $\boldsymbol{A}$ ) basal; $\boldsymbol{B})$ LPS activation; $\boldsymbol{C}$ ) RLX $60 \mathrm{ng} / \mathrm{ml}$ and LPS; and $\boldsymbol{D}$ ) RLX 60 $\mathrm{ng} / \mathrm{ml}$ plus L-NMMA and LPS. Nuclei are counterstained with hematoxylin. Magnification: $\times 200$. Bar $=100 \mu \mathrm{m}$. 
Fig. 5

\title{
A $\quad$ B $\quad$ C $\quad$ D
}

\section{P-selectin}

\author{
VCAM-1
}

ICAM-1

$\beta$-actin
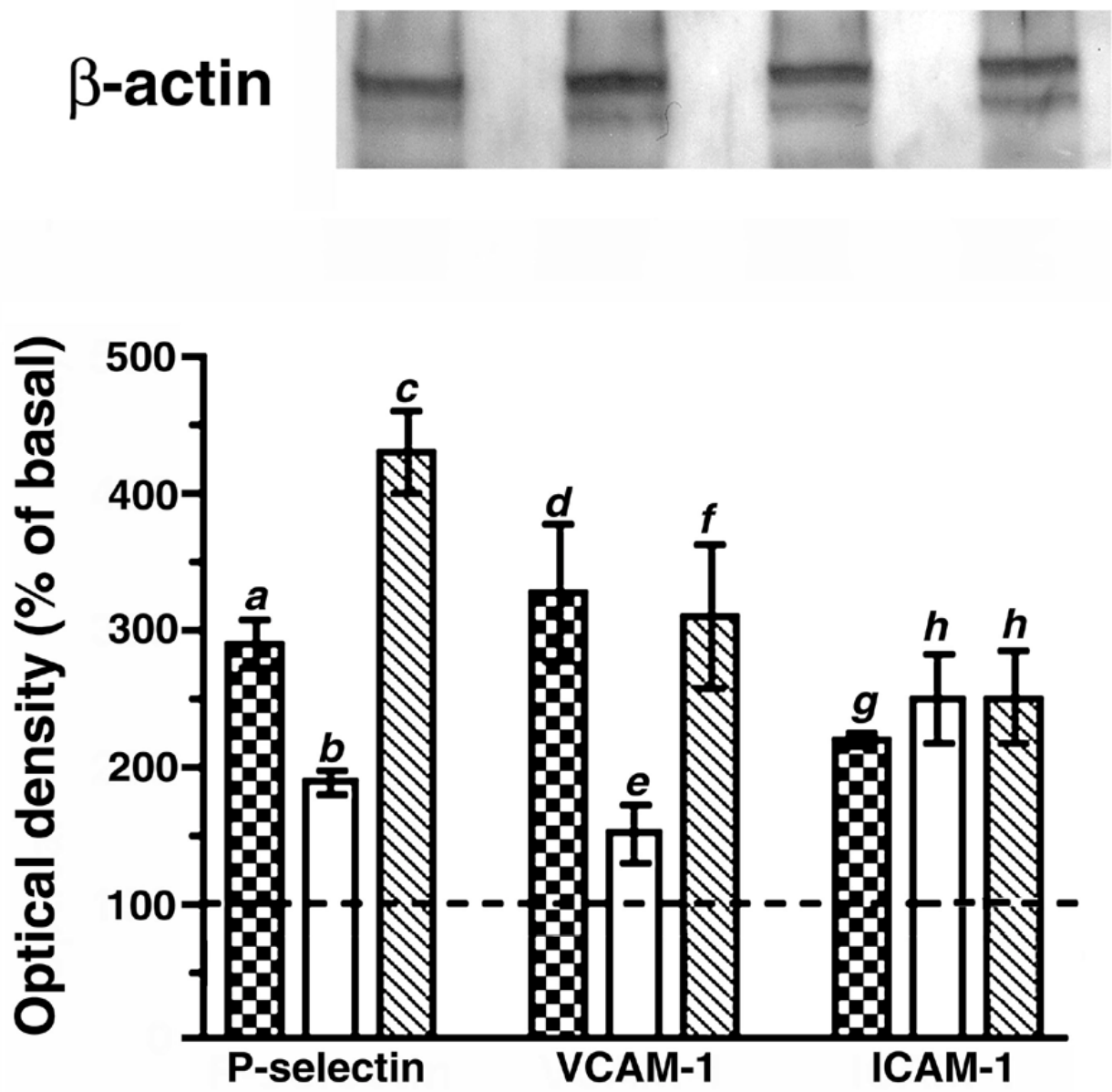

Figure 5. Analysis of P-selectin, VCAM-1, and ICAM-1 protein expression by Western blot. Lanes: $(A)$ basal; $(B)$ LPS activation; (C) RLX $60 \mathrm{ng} / \mathrm{ml}$ and LPS; and (D) RLX $60 \mathrm{ng} / \mathrm{ml}$ plus L-NMMA and LPS. Columns: dotted, LPS activation; blank, RLX; striped, RLX + L-NMMA. The dashed line represents the basal values, assumed as $100 \%$. Significance of differences (one-way ANOVA, $n=3$ ): (a) $\mathrm{P}<0.001$ vs. basal; (b) $P<0.01$ vs. LPS; (c) $P<0.001$ vs. RLX alone; $(\boldsymbol{d}) P<0.05$ vs. basal; $(\boldsymbol{e}) P<0.05$ vs. LPS; $(\boldsymbol{f}) P<0.05$ vs. RLX alone; $(\boldsymbol{g}) P<0.05$ vs. basal; and $(\boldsymbol{h})$ not significant vs. LPS. 
Fig. 6
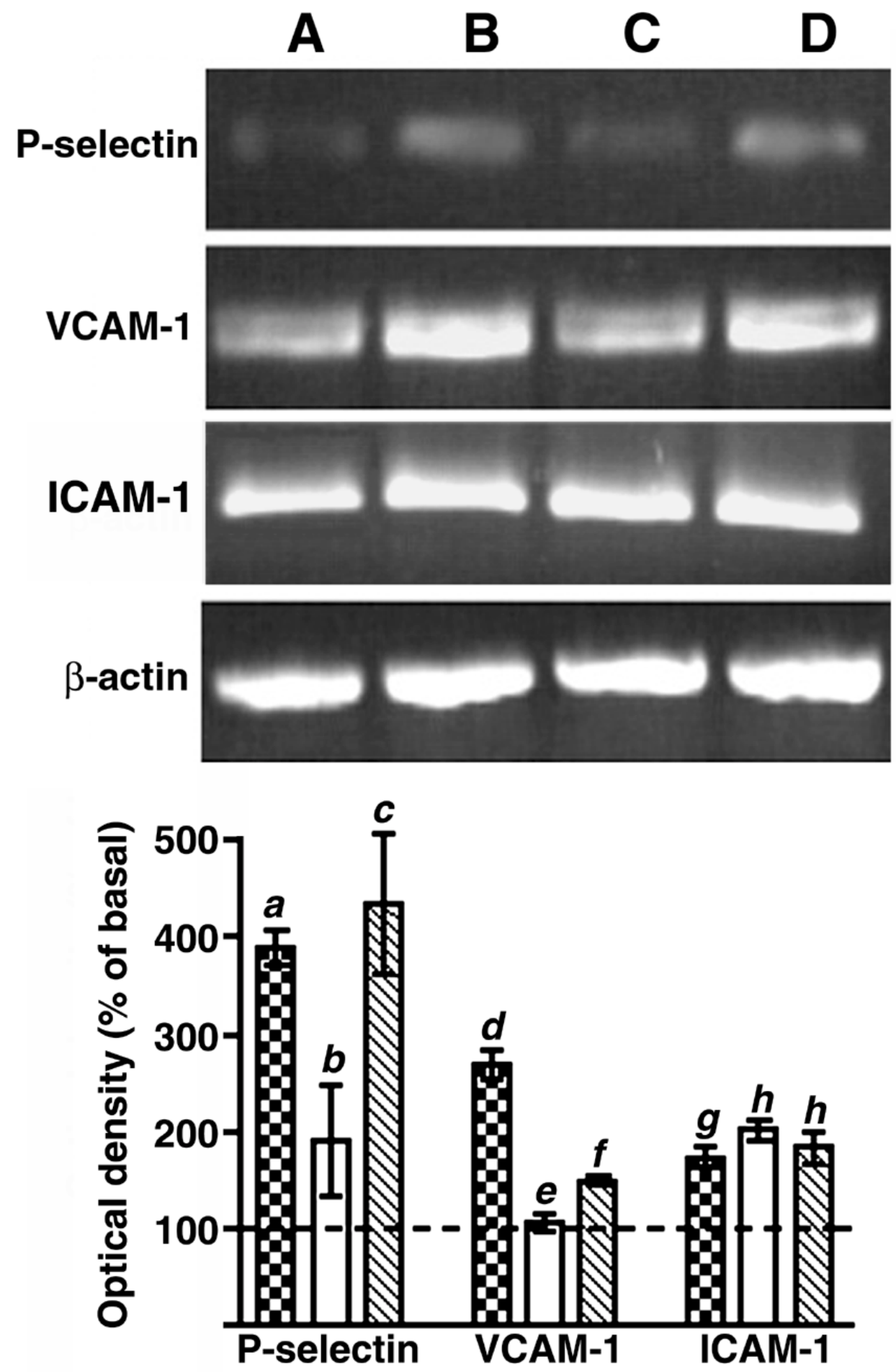

Figure 6. Analysis of P-selectin, VCAM-1, and ICAM-1 mRNA expression by RT-PCR. Lanes: $(A)$ basal; $(B)$ LPS activation; $(\boldsymbol{C})$ RLX $60 \mathrm{ng} / \mathrm{ml}$ and LPS; and $(\boldsymbol{D})$ RLX $60 \mathrm{ng} / \mathrm{ml}$ plus L-NMMA and LPS. Columns: dotted, LPS activation; blank, RLX; striped, RLX + L-NMMA. The dashed line represents the basal values, assumed as $100 \%$. Significance of differences (one-way ANOVA, $n=3$ ): (a) $P<0.01$ vs. basal; (b) $P<0.05$ vs. LPS; (c) $P<0.05$ vs. RLX alone; $(\boldsymbol{d}) P<0.001$ vs. basal; $(\boldsymbol{e}) P<0.001$ vs. LPS; $(\boldsymbol{f}) P<0.05$ vs. RLX alone; $(\boldsymbol{g}) P<0.05$ vs. basal; and $(\boldsymbol{h})$ not significant vs. LPS. 


\section{THE}

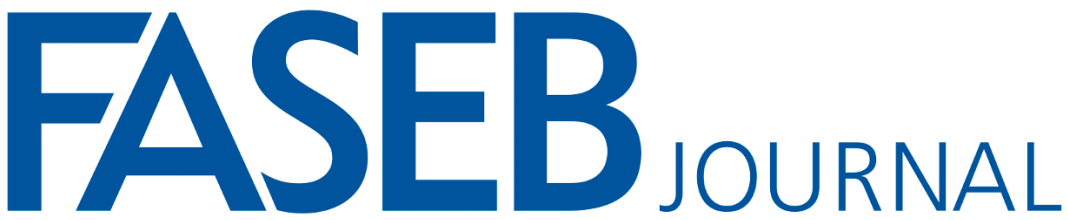

The Journal of the Federation of American Societies for Experimental Biology

\section{Relaxin inhibits lipopolysaccharide-induced adhesion of neutrophils to coronary endothelial cells by a nitric oxide-mediated mechanism}

Silvia Nistri, Laura Chiappini, Chiara Sassoli, et al.

FASEB J published online September 18, 2003

Access the most recent version at doi:10.1096/fj.03-0216fje

Subscriptions Information about subscribing to The FASEB Journal is online at

http://www.faseb.org/The-FASEB-Journal/Librarian-s-Resources.aspx

Permissions Submit copyright permission requests at:

http://www.fasebj.org/site/misc/copyright.xhtml

Email Alerts Receive free email alerts when new an article cites this article - sign up at http://www.fasebj.org/cgi/alerts 